\title{
Chiral Ligand Exchange Chromatography: Separation of Enantiomeric Mixtures of Underivatized $\alpha$-Amino Acids under UV Detection
}

\author{
Patricia M. P. Nazareth and Octavio A. C. Antunes* \\ Instituto de Química, Universidade do Federal do Rio de Janeiro, CT, Bloco A, Lab. 641, 21945-970 \\ Rio de Janeiro - RJ, Brazil
}

\begin{abstract}
Misturas de enantiômeros de alanina, serina, threonina, valina, metionina, leucina e norleucina foram resolvidas cromatograficamente (e reprodutivelmente), através de cromatografia líquida de alta eficiência (CLAE) com fase reversa, por troca de ligantes, utilizando-se L-prolina, L-hidroxiprolina ou $N, N$-dimetil-L-fenilalanina $\left(2 \mathrm{mmol} \mathrm{L}^{-1}\right)$ e $\mathrm{Cu}\left(\mathrm{CH}_{3} \mathrm{COO}\right)_{2}\left(1 \mathrm{mmol} \mathrm{L}^{-1}\right)$ em água ou em água/ metanol. A utilização de água/metanol leva a uma grande diminuição dos tempos de retenção dos $\alpha$ amino ácidos mais hidrofóbicos, preservando a separação enantiomérica. O pH precisa ser alto o bastante para permitir a presença de grupos $-\mathrm{NH}_{2}$ livres, o que torna a complexação com $\mathrm{Cu}$ (II) mais fácil. $\alpha$-Amino ácidos conformacionalmente mais restritos, como a L-prolina e a L-hidroxiprolina, conduziram a separações enantioméricas menores. A formação de complexos pseudo-homoquirais e pseudo-heteroquirais, por troca de ligantes, que é cinética e termodinamicamente controlada, desempenha um papel fundamental para a separação enantiomérica desejada. Esta metodologia simples e barata pode ser usada em qualquer laboratório envolvido em síntese de $\alpha$-amino ácidos.
\end{abstract}

Enantiomeric mixtures of alanine, serine, threonine, valine, methionine, leucine and norleucine were resolved in ligand exchange reversed phase HPLC (reproducibly), by using L-proline, Lhydroxyproline or $N, N$-dimethyl-L-phenylalanine $\left(2 \mathrm{mmol} \mathrm{L}^{-1}\right)$ and $\mathrm{Cu}\left(\mathrm{CH}_{3} \mathrm{COO}\right)_{2}\left(1 \mathrm{mmol} \mathrm{L}^{-1}\right)$ in water or in water/methanol. The latter mobile phase greatly decreased the retention time of the more hydrophobic $\alpha$-amino acids, preserving enantioseparation. $\mathrm{pH}$ must be high enough to allow the presence of free $-\mathrm{NH}_{2}$ groups in order to make the complexation with $\mathrm{Cu}$ (II) easier. The more restricted conformation of L-proline and L-hydroxyproline led to lower enantioseparations. The ligand exchange formation of pseudo-homochiral and pseudo-heterochiral complexes, thermodynamically and kinetically controlled, plays a fundamental role for the desired enantiomeric chromatographic separation. This simple and inexpensive methodology can be used routinely by any laboratory involved in $\alpha$-amino acid synthesis.

Keywords: $\alpha$-amino acids, HPLC, pseudo-homochiral, pseudo-heterochiral

\section{Introduction}

In asymmetric synthesis and catalysis ${ }^{1-4}$ either a selective production of one enantiomer from a pro-chiral substrate, or a specific reaction from one enantiomer of a racemate, is proposed, thereby producing an enriched mixture or an enantiopure compound. An increasing number of laboratories have been carrying out activities for obtaining pure enantiomers, or highly enriched enantiomeric mixtures, which could be used in many specific applications. The synthesis ${ }^{5,6}$ and the use $^{7}$ of chiral $\alpha$-amino acids have particular importance in bioorganic

* e-mail: octavio@iq.ufrj.br and in medicinal chemistry. Therefore, reproducible methods to analyze enantiomeric mixtures of these compounds are needed to be used routinely.

High Performance Liquid Chromatography (HPLC) is one of the most powerful tools to analyze enantiomeric mixtures. ${ }^{8-18}$ In HPLC this resolution is only possible by the transient formation of a pair of diastereomers with different chemical properties and consequently different retentivities. For this purpose enantiomers are submitted to chromatography either on a chiral stationary phase (CSP) or using an achiral stationary phase with a chiral modifier in the mobile phase.

The commercially available chiral stationary phases (CSP) for HPLC, although very useful, ${ }^{19,20}$ are extremely expensive, with short lifetimes and limited ranges. 
Therefore, L-proline, ${ }^{21-24}$ L-hydroxyproline ${ }^{25}$ and $N, N$ dimethyl-L-phenylalanine ${ }^{10}$ were used as chiral selectors in the mobile phase. These compounds, combined with $\mathrm{Cu}$ (II) salts and mixtures of different DL- $\alpha$-amino acids, were shown to produce diastereoisomeric complexes with the desired different retentivities in reversed phase liquid chromatography. However, since previously published work emphasized the use of cation-exchange columns and/ or fluorescence detection, ${ }^{21-25}$ there is a need for a routine method, without derivatization, suitable for synthetic samples.

Based on these facts, we have been working on improved procedures for the resolution of enantiomeric mixtures of unprotected, underivatized $\alpha$-amino acids by chiral ligand exchange chromatography (CLEC).

The purpose of the present paper is, therefore, to describe an improved, simple and inexpensive method to analyze enantiomeric mixtures of $\alpha$-amino acids, suitable to be used routinely by any group working on the synthesis of $\alpha$-amino acids as well as to describe the importance of the chiral selector structure to the desired enantioseparations and its implications on the chromatographic parameters.

\section{Material and Methods}

\section{Chemicals}

DL-alanine, DL-serine, DL-threonine, DL-leucine, DLvaline, DL-methionine, DL-norleucine, L-alanine, Lserine, L-threonine, L-leucine, L-valine, L-methionine, Lnorleucine, D-alanine, D-valine, D-leucine, Lhydroxyproline and $N, N$-dimethyl-L-phenylalanine were obtained from Sigma (St. Louis, MO, USA); L-proline was obtained from Controltec Química Fina Ltda. (Rio de Janeiro, RJ, Brazil); methanol (LC-grade) was from Vetec (Rio de Janeiro, RJ, Brazil); copper(II) acetate was obtained from Merck (Darmstadt, Germany). Water was purified with an Ultra Pure Water System- Milli-Q Plus from Millipore ${ }^{\text {TM }}$ (Bedford, MA, USA).

\section{Instrumentation}

A Shimadzu LC-10AS ${ }^{\mathrm{TM}}$ high-performance liquid chromatograph (Shimadzu, Kyoto, Japan), equipped with a Rheodyne $^{\mathrm{TM}}$ (Cotati, CA, USA) model 7125 injection valve, with a $20 \mu \mathrm{L}$ sampling loop, a Supelcosil $\mathrm{LC}_{-} \mathrm{C}_{18} \mathrm{DB}^{\mathrm{TM}}$ column $(250 \mathrm{~mm} \times 4.6 \mathrm{~mm})$ from Supelco ${ }^{\mathrm{TM}}$ (Bellefonte, PA, USA), with $5 \mu \mathrm{m}$ particle size and $10 \mathrm{~nm}$ pore diameter, and a Shimadzu Model SPD-10AV ${ }^{\mathrm{TM}}$ variable wavelength UV detector, was used. Detection was at $254 \mathrm{~nm}$. The chromatograms were recorded and integrated with a Chromatopac C-R6A ${ }^{\mathrm{TM}}$ processing system from Shimadzu.

\section{Sample preparation and $k$ values}

Aqueous solutions of the enantiomeric mixtures and of the L-isomers of the $\alpha$-amino acids were prepared with a final concentration of $0.5 \mathrm{mg} \mathrm{mL}^{-1}$. These solutions were filtered through an Iso-Disc N-34 nylon membrane $(0.45 \mu \mathrm{m} \times 3 \mathrm{~mm})$ from Supelco ${ }^{\mathrm{TM}}$, and analyzed several times. To determine $\mathrm{k}$, the column parameter $\mathrm{t}_{\mathrm{M}}$ was measured through unretained sodium nitrate $\left(\mathrm{t}_{\mathrm{M}}=3.4 \mathrm{~min}\right)$.

\section{Preparation of the chiral mobile phase}

L-proline, L-hydroxyproline and $N, N$-dimethyl-Lphenylalanine $\left(2 \mathrm{mmol} \mathrm{L}^{-1}\right)$ and $\mathrm{Cu}\left(\mathrm{CH}_{3} \mathrm{COO}\right)_{2}\left(1 \mathrm{mmol} \mathrm{L}^{-1}\right)$ were dissolved in water or in water/methanol. The final measured $\mathrm{pH}$ was 5.0 and in some cases was adjusted to 6.0. These solutions were filtered through Nylon 66 membranes $(0.2 \mu \mathrm{m} \times 47 \mathrm{~mm})$ from Supelco ${ }^{\mathrm{TM}}$. It is worth to point out that, whenever the mobile phase is prepared, the solution always showed a blue color and an absorption background under UV detection. To decrease this effect, in practical terms, the whole system was washed with the mobile phase until the detector base line stabilized, and was then zeroed. Therefore, in order to have a detectable signal without interference of the mobile phase, the sample must have appropriates concentrations, such as those used in the present work, allowing it to have a signal higher than that of the mobile phase. In the present work a concentration of $0.5 \mathrm{mg} \mathrm{mL}^{-1}$ for the enantiomeric mixtures, $2 \mathrm{mmol} \mathrm{L}^{-1}$ for the chiral selector and $1 \mathrm{mmol} \mathrm{L}^{-1}$ for the $\mathrm{Cu}\left(\mathrm{CH}_{3} \mathrm{COO}\right)_{2}$ were successfully used.

\section{Results and Discussion}

Retentivity and enantioselectivity obtained for racemates using L-proline, L-hydroxyproline or N,N-dimethyl-Lphenylalanine

Using water as the mobile phase, good enantiomeric separations, displayed by the chromatographic enantioselectivity, $\alpha=k(\mathrm{~L}) / \mathrm{k}(\mathrm{D})$, were achieved for DLalanine, DL-valine and DL-methionine, by using L-proline as chiral selector. For DL-serine and DL-threonine the chiral selector L-proline proved not to be enantioselective (Table 1). The retention factors, $\mathrm{k}=\left(\mathrm{t}_{\mathrm{R}}-\mathrm{t}_{\mathrm{M}}\right) / \mathrm{t}_{\mathrm{M}}$, for DL-valine and DL-methionine were high. To reduce these retentivities, a new mobile phase containing methanol was used. In reversed phase chromatography, addition of a less polar 
solvent (e.g., methanol) increases the solvent strength. As a result a solvent mixture with better eluotropic capacity can be used, thereby resulting in smaller k values. For DLvaline $5 \%(\mathrm{v} / \mathrm{v})$ methanol in water was enough. However, for DL-methionine it was necessary to use $10 \%(\mathrm{v} / \mathrm{v})$ methanol in water. The use of this mobile phase also allowed the analyses of enantiomeric mixtures of leucine and norleucine.

The results for enantioselectivity factors $(\alpha)$ and retention factors $(\mathrm{k})$ were different with L-hydroxyproline (Table 2). Using water as the mobile phase, this ligand was not able to produce enantioselective separations for DLalanine, DL-serine, DL-threonine and DL-valine. In this case the retention factors found for these amino acids were smaller than those found with L-proline. Nevertheless, this ligand was able to yield the desirable separations for the more hydrophobic amino acids, methionine, norleucine and leucine. To lower the retentivities of these amino acids the use of $5 \%(\mathrm{v} / \mathrm{v})$ methanol in water as the mobile phase was enough.

$N, N$-dimethyl-L-phenylalanine produced the separation of all amino acids studied in the present work (Table 3). Using water as the mobile phase, for DL-alanine, DL-serine and DL-threonine the retention factors found were larger than those obtained with L-proline and Lhydroxyproline (Tables 1 and 2). To analyze the more hydrophobic $\alpha$-amino acids, DL-valine, DL-methionine, DL-norleucine and DL-leucine, $15 \%(\mathrm{v} / \mathrm{v})$ methanol in

Table 1. Retention factors and enantioselectivity for some $\alpha$-amino acids using L-proline as chiral mobile phase modifier

\begin{tabular}{|c|c|c|c|c|c|c|c|c|c|c|c|c|}
\hline \multirow[b]{2}{*}{$\alpha$-amino acid } & \multicolumn{3}{|c|}{ water } & \multicolumn{3}{|c|}{$5 \%(\mathrm{v} / \mathrm{v}) \mathrm{MeOH}$} & \multicolumn{3}{|c|}{$10 \%(\mathrm{v} / \mathrm{v}) \mathrm{MeOH}$} & \multicolumn{3}{|c|}{ pH 6} \\
\hline & $\mathrm{k}_{\mathrm{D}}$ & $\mathrm{k}_{\mathrm{L}}$ & $\alpha$ & $\mathrm{k}_{\mathrm{D}}$ & $\mathrm{k}_{\mathrm{L}}$ & $\alpha$ & $\mathrm{k}_{\mathrm{D}}$ & $\mathrm{k}_{\mathrm{L}}$ & $\alpha$ & $\mathrm{k}_{\mathrm{D}}$ & $\mathrm{k}_{\mathrm{L}}$ & $\alpha$ \\
\hline Alanine & 0.20 & 0.26 & 1.30 & & & & & & & & & \\
\hline Serine & 0.18 & 0.18 & 1.00 & & & & & & & 0.30 & 0.30 & 1.00 \\
\hline Threonine & 0.35 & 0.35 & 1.00 & & & & & & & 0.22 & 0.22 & 1.00 \\
\hline Valine & 1.60 & 6.90 & 4.30 & 1.13 & 2.52 & 2.23 & 0.79 & 0.79 & 1.00 & & & \\
\hline Methionine & 2.59 & 5.41 & 2.10 & & & & 1.23 & 1.54 & 1.25 & & & \\
\hline Norleucine & & & & & & & 2.54 & 3.43 & 1.35 & & & \\
\hline Leucine & & & & & & & 2.26 & 2.80 & 1.24 & & & \\
\hline
\end{tabular}

Conditions: column, SUPELCOSIL LC-18-DB; eluent, $1 \mathrm{mmol} \mathrm{L}^{-1} \mathrm{Cu}(\mathrm{OAc})_{2}$ and $2 \mathrm{mmol} \mathrm{L}^{-1}$ of the chiral selector; flow rate, $1.0 \mathrm{~mL} \mathrm{~min}^{-1}$.

Table 2. Retention factors and enantioselectivity for some a-amino acids using L-hydroxyproline as chiral mobile phase modifier

\begin{tabular}{|c|c|c|c|c|c|c|c|c|c|}
\hline \multirow[b]{2}{*}{$\alpha$-amino acid } & \multicolumn{3}{|c|}{ water } & \multicolumn{3}{|c|}{$5 \%(\mathrm{v} / \mathrm{v}) \mathrm{MeOH}$} & \multicolumn{3}{|c|}{$\mathrm{pH} 6$} \\
\hline & $\mathrm{k}_{\mathrm{D}}$ & $\mathrm{k}_{\mathrm{L}}$ & $\alpha$ & $\mathrm{k}_{\mathrm{D}}$ & $\mathrm{k}_{\mathrm{L}}$ & $\alpha$ & $\mathrm{k}_{\mathrm{D}}$ & $\mathrm{k}_{\mathrm{L}}$ & $\alpha$ \\
\hline Alanine & 0.15 & 0.15 & 1.00 & & & & & & \\
\hline Serine & 0.14 & 0.14 & 1.00 & & & & 0.31 & 0.31 & 1.00 \\
\hline Threonine & 0.15 & 0.15 & 1.00 & & & & 0.39 & 0.39 & 1.00 \\
\hline Valine & 1.87 & 1.87 & 1.00 & 0.77 & 0.77 & 1.00 & & & \\
\hline Methionine & 2.30 & 3.1 & 1.35 & 1.33 & 1.58 & 1.19 & & & \\
\hline Norleucine & 4.17 & 5.78 & 1.38 & 2.44 & 2.95 & 1.21 & & & \\
\hline Leucine & 4.01 & 5.32 & 1.33 & 2.29 & 2.68 & 1.17 & & & \\
\hline
\end{tabular}

Conditions: column, SUPELCOSIL LC-18-DB; eluent, $1 \mathrm{mmol} \mathrm{L}^{-1} \mathrm{Cu}(\mathrm{OAc})_{2}$ and $2 \mathrm{mmol} \mathrm{L}^{-1}$ of the chiral selector; flow rate, $1.0 \mathrm{~mL} \mathrm{~min}^{-1}$.

Table 3. Retention factors and enantioselectivity for some a-amino acids using $N, N$-dimethyl-L-phenylalanine as chiral mobile phase modifier

\begin{tabular}{lcccccccc}
\hline & \multicolumn{3}{c}{ water } & \multicolumn{3}{c}{$15 \%(\mathrm{v} / \mathrm{v}) \mathrm{MeOH}$} & \multicolumn{2}{c}{$20 \%(\mathrm{v} / \mathrm{v}) \mathrm{MeOH}$} \\
\hline$\alpha$-amino acid & $\mathrm{k}_{\mathrm{D}}$ & $\mathrm{k}_{\mathrm{L}}$ & $\alpha$ & $\mathrm{k}_{\mathrm{D}}$ & $\mathrm{k}_{\mathrm{L}}$ & $\alpha$ & $\mathrm{k}_{\mathrm{D}}$ & $\mathrm{k}_{\mathrm{L}}$ \\
\hline Alanine & 0.44 & 0.73 & 1.70 & & & & & \\
Serine & 0.60 & 0.87 & 1.40 & & & & & \\
Threonine & 0.86 & 1.25 & 1.50 & & & & & \\
Valine & & & & 0.91 & 2.62 & 2.88 & & \\
Methionine & & & & 2.11 & 3.21 & 1.52 & & \\
Norleucine & & & & 3.27 & 8.91 & 2.72 & 1.69 & 3.45 \\
Leucine & & & 2.75 & 6.06 & 2.20 & 1.37 & 2.67 & 1.95 \\
\hline
\end{tabular}

Conditions: column, SUPELCOSIL LC-18-DB; eluent, $1 \mathrm{mmol} \mathrm{L}^{-1} \mathrm{Cu}(\mathrm{OAc})_{2}$ and $2 \mathrm{mmol} \mathrm{L}^{-1}$ of the chiral selector; flow rate, $1.0 \mathrm{~mL} \mathrm{~min}^{-1}$. 
water was found to be quite suitable. However, to lower the retentivities of DL-norleucine and DL-leucine, 20\% $(\mathrm{v} / \mathrm{v})$ methanol in water was necessary.

Since conformational constraints are greater in Lproline and L-hydroxyproline than in $N, N$-dimethyl-Lphenylalanine, the structure of the chiral selector plays an important role in the recognition and, therefore, in the separation of the enantiomeric mixtures.

In this work, independent of the chiral selectors used, the observed (enantiomeric) order of elution was the same, as expected: The D-enantiomer was eluted before the Lenantiomer. The peak identity was checked by injecting L-enantiomers, for all a-amino acids, and by injecting the D-enantiomers of alanine, valine and leucine.

It is not difficult to explain enantiomeric separations, considering the (dynamic) formation of a homochiral ${ }^{1,2}$ complex between the ligands and $\mathrm{Cu}(\mathrm{II})$. This homochiral complex in the presence of an enantiomeric mixture of $\alpha$ amino acids is submitted to a process of ligand exchange. The extension of this ligand exchange is constrained by thermodynamics, that is, differences between equilibrium constants, and kinetics, or the rates of ligand exchange reactions. ${ }^{26}$ The result, when chiral separation is achieved, is the formation of pseudo-homochiral and pseudoheterochiral complexes (Figure 1), with the necessary lifetimes and different retentivities. Chiral recognition, responsible for the formation of the new complexes, is a very well described process based on the 'three points interactions' concept. ${ }^{13,16,18}$ The formation of these complexes, therefore, resulted from different interactions. Consequently, complexes with different stabilities (and life-times) are formed. The bases for enantiomeric resolution are, principally, the differences in lability of the pseudo-homochiral and pseudo-heterochiral complexes that can (although not always) result in different interactions with the stationary phase and hence different chromatographic retentivities. It is worth pointing out that the complexes shown in the present work were considered to be trans, based on the work of Jackovitz et al. ${ }^{27}$ and Jackovitz and Walter, ${ }^{28}$ who isolated similar complexes and, based on their infrared spectra and symmetry considerations, stated their stereochemistry as trans. pseudo-homochiral complex

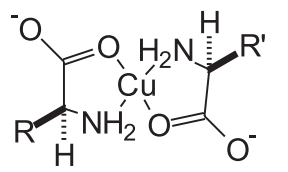

L-Chiral selector L-aa pseudo-heterochiral complex

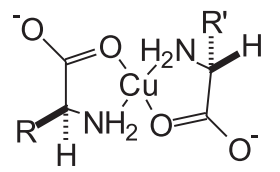

L-Chiral selector D-aa
Figure 1. Pseudo-homochiral and pseudo-heterochiral complexes.

\section{Effect of the $p H$ of the mobile phase}

DL-alanine, DL-valine, DL-methionine, DL-norleucine and DL-leucine mixtures were analyzed without adjustment of the mobile-phase $\mathrm{pH}$. However, for some $\alpha$-amino acids, mobile phase $\mathrm{pH}$ adjustment (from 5 to 6 ) is necessary for the required enantioselective separation..$^{12,22,29,30} \mathrm{This} \mathrm{pH}$ adjustment is necessary to provide the free amino groups $\left(\mathrm{RNH}_{3}{ }^{+} \rightarrow \mathrm{RNH}_{2}\right)$, which are needed for proper coordination to $\mathrm{Cu}$ (II).

In aqueous solution, equilibrium exists between the zwiterions and the anionic and cationic forms of the $\alpha$ amino acids (Scheme 1). The main form of the $\alpha$-amino acid present in solution depends on the $\mathrm{pH}$ of the solution and on the nature $\left(\mathrm{pK}_{\mathrm{a}}\right.$ of $\left.\mathrm{RNH}_{3}^{+}\right)$of the $\alpha$-amino acid. With increasing $\mathrm{pH}$ the concentration of $\mathrm{RNH}_{2}$ increases, thus facilitating the coordination to $\mathrm{Cu}(\mathrm{II})$.

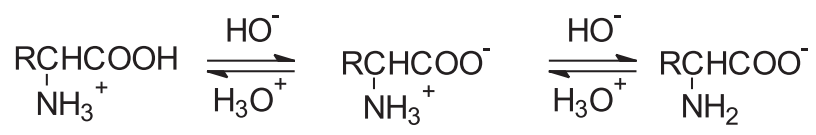

Because of the lack of chromatographic enantiomeric resolution for DL-serine and DL-threonine enantiomeric mixtures with L-proline and L-hydroxyproline, the $\mathrm{pH}$ was adjusted to 6 to try to make the coordination easier and as an attempt to produce complexes having six membered chelate rings on one side, ${ }^{10,29}$ as shown in Figure 2. However, the desired enantioseparation was not achieved (Tables 1 and 2).

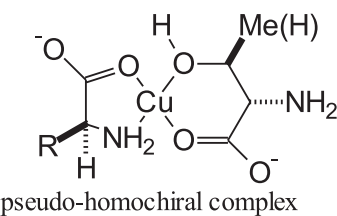

pseudo-homochiral complex

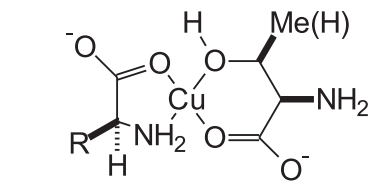

pseudo-heterochiral complex
Figure 2. Diastereoisomeric complexes with DL-threonine or DLserine.

Therefore, at least in these cases (DL-serine and DLthreonine), the hydrophobic interactions between the complexes formed between the $\alpha$-amino acids, the chiral ligands (L-proline or L-hydroxyproline) and the $\mathrm{Cu}$ (II) ions were not appropriate for enantioselective separation, which was achieved, under the same conditions, by using $\mathrm{N}, \mathrm{N}$ dimethyl-L-phenylalanine as chiral ligand.

Since, at higher $\mathrm{pH}$ the concentration of free $-\mathrm{NH}_{2}$ groups is higher, not only the six membered chelates, but also the corresponding five membered chelates, would be present, in rapid equilibrium, thereby changing $\mathrm{pH}$ alone 
did not favor the six membered chelates and, consequently, did not result in the desired enantioseparation. Additionally, the life-times of these species, and/or the differences in their interaction with the stationary phase would be so small that the two diastereoisomeric complexes would end up coalescing.

The effect of the presence of the hydroxy group in complex formation and in chiral recognition is more suitable to be seen using L-hydroxyproline as chiral selector. In these cases, as above, at least four complexes would be formed (Figure 3 ).

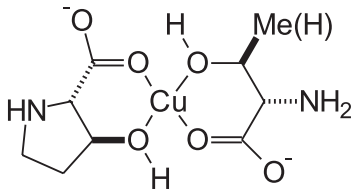<smiles></smiles>

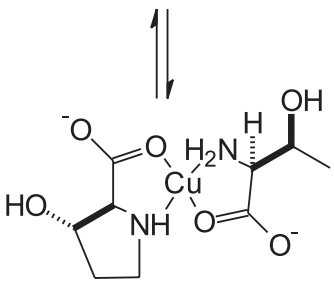

pseudo-homochiral complex

L-Chiral selector L-aa

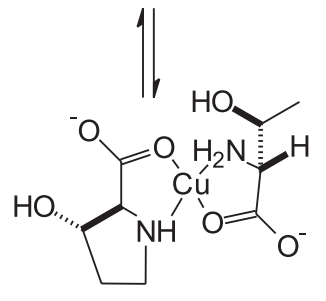

pseudo-heterochiral complex L-Chiral selector D-aa

Figure 3. Diastereoisomeric complexes with DL-threonine or DLserine and L-hydroxyproline.

$\mathrm{pH}$ adjustments above 6 were tried. However, the solutions showed such intense blue color and the (UV) background of the mobile phase was so high that detection was impossible.

\section{The hydrophobic interaction between chiral selectors and $\alpha$-amino acids}

Diastereomeric complexes have different stabilities in solution. 1,2,16,26 These differences have been widely exploited in asymmetric catalysis, from which the terms homochiral and heterochiral have arisen. ${ }^{1,2}$ After ligand exchange, the hydrophobic interactions between the $\alpha$ amino acids and the L-ligand were observed to be more effective, in the complex, for the L- $\alpha$-amino acid. In this case the side chains of the L- $\alpha$-amino acid and L-ligand (the chiral selector) are on the same side, therefore leading to stronger hydrophobic interactions, outside the complex, with the apolar stationary phase. Davankov and Kurganov ${ }^{9}$ were the first to realize the importance of such interactions. The greater the hydrophobicity of the $\alpha$-amino acid side chain, the greater is the interaction between the L- $\alpha$-amino

acid and the L-ligand, and the greater is the retentivity of the pseudo-homochiral complex. , 10,12,31 $^{8}$

Having in mind the structural relationship between Lhydroxyproline and DL-threonine and DL-serine, it would be expected that there would be a more reliable chiral recognition between the L-ligand and these hydroxy amino acids than with the compounds lacking the hydroxy group. However, no enantioseparation was achieved in these cases (DL-threonine and DL-serine) or with less hydrophobic $\alpha$ amino acids (Table 2), indicating that the presence of a polar hydroxy group in the chiral selector decreased the hydrophobic interaction of the diastereoisomeric complexes and the stationary phase. For DL-methionine, DL-norleucine and DL-leucine, the presence of the polar hydroxy group in the L-ligand lead to lower retentivities. Such an effect was emphasized in the case of complexes of L- $\alpha$-amino acids, in which the hydrophobic interactions are expected to be more effective. For the complexes of D$\alpha$-amino acids the change in their retentivities was not so important due to their smaller interaction with the stationary phase. As an overall effect, the use of Lhydroxyproline allowed the more hydrophobic DL- $\alpha$ amino acids to be separated in water, but not by using $5 \%$ $(\mathrm{v} / \mathrm{v})$ methanol in water as the mobile phase (Table 2).

With the purpose of observing how the increase of the hydrophobicity of the chiral selector would affect the selectivity, $N, N$-dimethyl-L-phenylalanine was used as a chiral selector. Such a chiral selector, besides having an aromatic (benzene) ring, that provides good hydrophobicity, has also an $N, N$-dimethyl group that increases basicity and hydrophobicity. These characteristics were enough to overwhelm the difficulties presented by the other ligands in the chiral separation of DL-serine and DL-threonine. On the one hand, the basicity of this selector proved to be strong enough to lead to thermodynamically and kinetically stable complexes capable of being analyzed while, on the other hand, hydrophobicity was strong enough to overcome the presence of a polar hydroxy group in the neighborhood of the hydrophobic interaction. This shows that the third point of contact through the hydrophobic interactions is important for enantioseparation.

DL-valine, DL-methionine, DL-norleucine and DLleucine showed much greater interaction with this chiral selector and the stationary phase than with the others. For DL-valine, DL-methionine, DL-norleucine and DL leucine, the interaction is so great that it was necessary to use $15 \%(\mathrm{v} / \mathrm{v})$ methanol in water as the mobile phase to analyze these enantiomeric mixtures, and $20 \%$ (v/v) methanol in water to reduce the retentivities of DLnorleucine and DL -leucine (Table 3 ). 


\section{Conclusions}

The present work describes improved procedures to analyze enantiomeric mixtures of some $\alpha$-amino acids. The concentration range is compatible with synthetic samples. The procedure, based on CLEC, using $1 \mathrm{mmol} \mathrm{L}^{-1}$ $\mathrm{Cu}(\mathrm{OAc})_{2}$ and $2 \mathrm{mmol} \mathrm{L}^{-1}$ of the chiral selector, with UV detection, without derivatization, is inexpensive and reliable for routine samples. CLEC was made possible through the transient formation of diastereoisomeric pseudo-homo- and pseudo-heterochiral complexes between the chiral selector, $\mathrm{Cu}$ (II) and the chiral $\alpha$-amino acids. The importance of the basicity and hydrophobicity of the chiral selector is emphasized.

The design of new systems for enantioseparations would include, in the chiral selector, the presence of tertiary amino groups, the possibility of formation of only five membered ring chelates, a side chain amenable to good hydrophobic interactions with the stationary phase, and mobile phases with lower background in the wavelengths to be used for detection.

For the first time the phenomena observed in chiral ligand exchange chromatography were treated in terms of the formation of exchangeable pseudo-homochiral and pseudo-heterochiral complexes, therefore linking them to the more general subject, chiral recognition, widely exploited in asymmetric catalysis.

\section{Acknowledgments}

Financial support from CNPq, CAPES, FAPERJ, FUJB, FINEP (PADCT, FNDCT) and PRONEX is gratefully acknowledged.

\section{References}

1. Girard, C.; Kagan, H.B.; Angew. Chem. Int. Ed. 1998, 37, 2922.

2. Noyori, R.; Asymmetric Catalysis in Organic Synthesis, John Wiley \& Sons, Inc.: New York, 1994.

3. Ojima, I.; Catalytic Asymmetric Synthesis, VCH Publishers, Inc.: New York, 1993.

4. Sheldon, R.A.; Chirotechnology: Industrial Synthesis of Optically Active Compounds, Marcel Dekker, Inc.: New York, 1994.

5. Duthaler R.O.; Tetrahedron 1994, 50, 1539.

6. Williams, R.M.; Synthesis of Optically Active $\alpha$-Amino Acids, Pergamon Press: Oxford, 1989.
7. Coppola, G.M.; Schuster, H.F.; Asymmetric Synthesis: Construction of Chiral Molecules using Amino Acids, John Wiley \& Sons, Inc.: New York, 1987.

8. Gilon, C.; Leshem, R.; Grushka, E.; Anal. Chem. 1980, 52, 1206.

9. Davankov, V.A.; Kurganov, A.A.; Chromatographia 1983, 17, 686.

10. Wernicke, R.; J. Chromatogr. Sci. 1985, 23, 39.

11. Pirkle, W.H.; Pochapsky, T.C.; Chem. Rev. 1989, 89, 347.

12. Galaverna, G.; Corradini, R.; DeMunari, E.; Dossena, A.; Marchelli, R.; J. Chromatogr. A 1993, 657, 43.

13. Davankov, V.A.; J. Chromatogr. A 1994, 666, 55.

14. Husain, S.; Sekar, R.; Rao, R.N.; J. Chromatogr. A 1994, 687, 351.

15. Husain, S.; Sekar, R.; Rao, R.N.; Indian Drugs 1997, 34, 127.

16. Pirkle, W.H.; Chirality 1997, 9, 103.

17. Galaverna, G.; Corradini, R.; Dossena, A.; Chiavaro, E.; Marchelli, R.; Dallavalle, F.; Folesani, G.; J. Chromatogr. A 1998, 829, 101.

18. Hyun, M.H.; Ryoo, J.J.; Pirkle, W.H.; J. Chromatogr. A 2000, 886, 47.

19. Gonçalves, L.P.B.; Antunes, O.A.C.; Pinto, G.F.; Oestreicher, E.G.; Tetrahedron: Asymmetry 2000, 11, 1465.

20. Arcuri, M.B.; Antunes, O.A.C.; Sabino, S.J.; Pinto, G.F.; Oestreicher, E.G.; Amino Acids 2000, 19, 477.

21. Hare, P.E.; Gil-Av, E.; Science 1979, 204, 1226.

22. Gil-Av, E.; Tishbee, A.; Hare, P.E.; J. Am. Chem. Soc. 1980, $102,5115$.

23. Horikawa, R.; Sakamoto, H.; Tanimura, T.; J. Liq. Chromatogr. 1986, 9, 537

24. Yamazaki, S.; Saito, K.; Tanimura, T.; J. Liq. Chromatogr. 1994, 17, 2559.

25. Davankov, V.A.; Zolotarev, Y.A.; J. Chromatogr. 1978, 155, 303.

26. Douglas, B.; McDaniel, D.; Alexander, J.; Concepts and Models of Inorganic Chemistry, $3^{\text {rd }}$ ed., John Wiley \& Sons, Inc.: New York, 1994.

27. Jackovitz, J.F.; Durkin, J.A.; Walter, J.L.; Spectrochim. Acta A 1967, 23, 67 .

28. Jackovitz, J.F.; Walter, J.L.; Spectrochim. Acta 1966, $22,1393$.

29. Gilon, C.; Leshem, R.; Grushka, E.; J. Chromatogr. 1981, 203,365

30. Lindner, W.F.; Hirschbock, I.; J. Liq. Chromatogr. 1986, 9 , 551.

31. Gilon, C.; Leshem, R.; Tapuhi, Y.; Grushka, E.; J. Am. Chem. Soc. 1979, 101, 7612. 